\title{
Autoshaping of initial feeding and drinking reactions in newly hatched chicks
}

\author{
GUY WOODRUFF and M. DAVID STARR \\ University of Pennsylvania, Philadelphia, Pennsylvania 19174
}

\begin{abstract}
Newly hatched chicks were force-fed food and water throughout rearing, and food, water, or sand reinforcers during exposure to an omission-training procedure. The chicks were thus prevented from performing approach and contact responses to the reinforcer at any time in their lives. Nevertheless, the subjects displayed approach and species-specific feeding or drinking reactions directed toward an illuminated key paired with food or water, but not with sand. Illumination of a key either uncorrelated or negatively correlated with food or water did not engender appreciable responding. Feeding and drinking reactions were topographically distinct, determined by the type of reinforcer, but were not elicited by the reinforcer. These findings support a "learned release" view of autoshaping, according to which phylogenetically preorganized behavior patterns are triggered by distal stimuli paired with biologically significant proximal stimulation, and suggest a close relationship between autoshaping and primitive instances of visual object recognition.
\end{abstract}

Autoshaped responses often resemble those speciesspecific behavior patterns that are exhibited during reinforcement. For example, pigeons approach and peck at an illuminated key (conditioned stimulus, or CS) which signals grain presentations (unconditioned stimulus, or US) in much the same way that they approach and peck at grain presented in a hopper (for reviews of the literature, see Hearst \& Jenkins, 1974; Schwartz \& Gamzu, 1977). One account of this finding suggests that the form of an autoshaped response is determined by the form of response elicited by the reinforcer (Jenkins \& Moore, 1973; Moore, 1973; Peterson, Ackil, Frommer, \& Hearst, 1972; Staddon \& Simmelhag, 1971). However, several studies of autoshaping do not support this view. Woodruff and Williams (1976) found that local application of water USs to the oral cavity of pigeons elicited "mumbling" and swallowing responses, whereas the illuminated-key CS elicited approach, "bowing," and "rooting" contact responses, in addition to "mumbling" and swallowing. In this case, the CS released a complete species-specific water-seeking motor pattern (Craig, 1912), even though the US did not. The pigeons behaved toward the CS as if it were the sight of a pool or droplet of water, and did not perform solely those responses

This research was supported by NSF Grant GB $35319 \mathrm{X}$ to D. R. Williams and USPHS Grant MH-04202 to R. L. Solomon. We thank Douglas Fenner, Robert Morrison, and D. R. Williams for helpful discussions, and J. A. Hogan, P. Rozin, and R. L. Solomon for critical comments on an early version of the manuscript. M. David Starr is now at Educational Testing Service, Princeton, New Jersey 08540 . Reprints may be obtained from Guy Woodruff, University of Pennsylvania Primate Facility, Honey Brook, Pennsylvania 19344. elicited by the US. Other experiments have reported comparable findings in different species with different reinforcers (Timberlake \& Grant, 1975; Wasserman, 1973a).

Woodruff and Williams offered a "learned release" hypothesis to account for the form of autoshaped responses. They speculated that behaviors directed toward the CS reveal an innate motor organization, and that associative factors play an important role in determining which environmental stimuli orient and release these motor patterns. A background for this view comes from demonstrations that remarkably complex appetitive-consummatory or defensive motor patterns can exist in a "preformed" state in the neural circuitry of the brainstem, but their overt expression depends heavily upon external stimuli (Bullock, 1961; Glickman \& Schiff, 1967; Roberts \& Bergquist, 1968; Valenstein, 1969; von Holst \& von Saint Paul, 1963). "Learned release" assumes that those aspects of a natural reinforcing object that innately identify it as biologically significant (e.g., oral aspects of water for the pigeon) "selectively facilitate" (Glickman \& Schiff, 1967) a specific sequence of instinctive motor acts (e.g., approach, bow, and root with water for the pigeon), and that an external signal for the reinforcer can become a "learned releasing stimulus" (Segal, 1972) for components of the facilitated response pattern. In the usual autoshaping procedure, food or water is presented visually in a hopper and thereby releases and orients complete motor patterns (e.g., Jenkins \& Moore, 1973). However, the learned-release hypothesis asserts that only those aspects (typically proximal stimulation) of environmental objects that identify them as biologically significant and facilitate 
preorganized response patterns need be paired with the CS for autoshaping to occur.

Certain aspects of the learned-release hypothesis deserve further experimental scrutiny. One concerns the assertion that the autoshaped response is innately organized. The fact that Woodruff and Williams' subjects were adult pigeons raises the possibility that the species-specific drinking reactions released by the CS in their experiment arose from a developmental history of pairings of approach and contact with water. Ontogenetic factors, such as instrumental reinforcement, may have led to the preexperimental organization of the autoshaped behavior pattern, and repeated pairings of CS and US may have reinstated an oft-performed instrumental response sequence (for related notions, see Asratyan, 1965; Gamzu \& Williams, 1975). Another question concerns the generality of "learned release" across different USs. According to the hypothesis, local application of water should lead to species-specific, CSdirected drinking responses, while local application of food should lead to species-specific, CS-directed feeding responses. Thus, although water or food in the mandibles does not elicit full drinking (approach, bow, root) or feeding (approach, peck) reactions, respectively (Woodruff, Morrison, \& Williams, Note 1), an illuminated key paired with either of these USs should release the corresponding behavior pattern. Woodruff and Williams (1976) employed only water USs in their experiment.

The present study provides further evidence for the learned release hypothesis by arranging autoshaping with food, water, or sand as the oral US in chicks lacking a developmental history of approach and contact with the USs. Force-feeding during both rearing and presentation of USs in autoshaping prevented approach and contact responses to the food and water USs throughout the experiment. Sand was never made available to subjects, except by force-feeding during autoshaping sessions. Also, adventitious operant reinforcement of key-contact topographies was obviated during the experiment by an omission-training procedure which prevented close temporal pairings of USs with responses making contact with the CS (Williams \& Williams, 1969). If the learned-release hypothesis is correct, one could expect successful autoshaping of complete approach and contact patterns with food or water USs. The form of behavior patterns directed toward the CS should be quite different with food or water USs, as are the normal peck or drink reactions observed in chicks under natural circumstances (Hunt \& Smith, 1967). Responses directed toward food objects typically consist of rapid ballistic pecks with beak open at the moment of contact. Responses directed toward water droplets are slower extensions of the neck and head with beak closed, followed by "nibbling" or "scooping" motions of the mandibles during prolonged contact. Sand as the oral US should not support autoshaping to a visual CS with which it is paired. Although the sight of sand elicits pecking in newly hatched chicks, this predisposition declines over the course of the first weeks of life (Hogan, 1971). The oral aspects of sand probably fail to identify it as a significant item for the young chick.

\section{METHOD}

\section{Subjects}

Twenty domestic chicks (Gallus domesticus) were hatched in the laboratory and housed in groups of four chicks. Home cages were cardboard boxes $(40 \times 40 \times 40 \mathrm{~cm})$ located in a dimly lighted room throughout the experiment.

\begin{abstract}
Apparatus
The experimental space was a cardboard box $(30 \times 30 \times 30 \mathrm{~cm})$ located in a dark room. The walls of the box were painted flat black and the floor was covered by Sanicell bedding. The front wall contained two $2.54-\mathrm{cm}$-diam response keys, positioned $10 \mathrm{~cm}$ apart and $5 \mathrm{~cm}$ above the floor. Each key required $8 \mathrm{~g}$ force $(0.08 \mathrm{~N})$ to operate a microswitch and record a response. A $60-\mathrm{W}$ houselight was placed $60 \mathrm{~cm}$ above the floor of the chamber and illuminated the entire space through the open top of the box. A mirror $(8 \times 12 \mathrm{~cm})$ was positioned in the right front corner of the box, at an angle which prevented reflections from the response keys when illuminated. The mirror was necessary to alleviate the chicks' distress over separation from their home-cage companions (Marley \& Morse, 1966). Two 7-W Westinghouse Christmas bulbs were located behind each response key, and were used to transilluminate the keys with green or orange light. All programming and recording equipment was located in an adjacent room.
\end{abstract}

\section{Procedure}

Beginning on the 3rd day after hatching, the chicks were forcefed a wet chick starter mash three times daily, in the dark. On the 3rd or 4th day after hatching, a series of five to seven autoshaping sessions was initiated for each chick. Two daily $12-\mathrm{min}$ sessions were conducted, one in the morning and the other in the late afternoon. All chicks were observed by one or the other author stationed next to the experimental chamber. The observer noted the topography of each key-directed response during each session. The observers were highly familiar with both pecking and drinking topographies, due to previous experience in pilot experiments and general observations of both young and old domestic chickens. Key-directed responses were recorded by the observer in three categories: (1) orient and approach (with or without an ensuing contact response); (2) ballistic peck toward the stimulus, followed by rapid withdrawal of the head away from the stimulus; and (3) slow extension of the neck until the beak touched the stimulus, followed by maintained contact and "scooping" or "nibbling" motions of the mandibles. On several occasions, an independent observer viewed the course of a session via closed circuit television. Although systematic data were not taken from this observer, he was in virtually complete agreement with response classifications made by the experimenter stationed inside the test room.

Each group of four chicks per home cage was exposed to one of five conditions during training. The observer stationed beside the experimental chamber also administered USs to the subjects in the manner described below.

Group Dis-F. Four chicks experienced five sessions of a discriminative omission-training procedure with food as the US (see Sheffield, 1965; Williams \& Williams, 1969). Sessions were initiated on the afternoon of the 4th day after hatching, and consisted 
of 2036 -sec cycles. Each cycle contained a $30-\mathrm{sec}$ intertrial interval (ITI), followed by a 6-sec fixed-duration illumination of either key. For each chick, one key color (CS+) was followed by food (US), while the alternate key color (CS - ) was never followed by food. CS + and CS - each occurred 10 times per session in random order (Gellermann, 1933). The orange and green key colors designated as $\mathrm{CS}+$ and $\mathrm{CS}$ - were counterbalanced between subjects. An omission contingency was in effect, such that any contact with CS + resulted in omission of the scheduled US.

Food USs were delivered by hand. At the offset of $\mathrm{CS}+$, the overhead houselight was extinguished and the chick was gently removed by hand from the chamber. A 7-W bulb corresponding to the color of $\mathrm{CS}+$ was positioned next to the chamber and illuminated while the chick was held 3 to $5 \mathrm{~cm}$ beneath it. Next, a small amount of dry mash was inserted into the chick's beak by hand. The bulb was then extinguished, the chick was returned to the chamber, and the houselight was illuminated. The entire sequence required 8 to $10 \mathrm{sec}$ during the beginning of the ITI, and the chicks seldom showed signs of distress, either during or after such handling. At the offset of $\mathrm{CS}-$, the same procedure was followed, with the exceptions that no food was inserted in the chick's beak and the illuminated bulb beside the chamber corresponded in color to that of the CS - .

Group Dis-W. Four chicks were exposed to seven sessions of a discriminative omission-training procedure identical to that described for the previous group, with the exception that USs consisted of approximately $0.05 \mathrm{cc}$ water injected from an opaque syringe into the beak. The sessions were initiated on the afternoon of the 3rd day after hatching.

Group Dis-S. Four chicks were exposed to five sessions of a procedure identical to that described for the previous groups, with the exception that USs were several grains of sand inserted into the beak by hand. The sessions were initiated on the afternoon of the 4th day after hatching.

Group Ran-F. Four chicks were exposed to five sessions of a random-control procedure with food as the US (see Gamzu \& Williams, 1971; Rescorla, 1967). The procedure was similar in most respects to that described for the discriminative conditioning groups, with two major exceptions. Food USs were presented randomly and independently of key illuminations during each session, according to the output of a probability gate set at $p=.03$ and sampled once every $2 \mathrm{sec}$. An average of 10 USs were delivered each session, and USs were uncorrelated with CSs. However, CSs and USs could, and did, occasionally occur together. If a US was scheduled to be delivered during or just after a key illumination, the US was administered beneath an illuminated $7-\mathrm{W}$ bulb corresponding to the color of the CS. If a US was scheduled to be delivered churing an intertrial interval, the US was administered beneath an illuminated $7-W$ white bulb, corresponding to the color of the houselight. No omission contingency was in effect for contact responses to either CS. Sessions were initiated on the afternoon of the 4 th day after hatching.

Group Ran-W. Four chicks experienced seven sessions of a random-control procedure identical to that described for the previous group, with the exception that USs were each approximately $0.05 \mathrm{cc}$ water. The sessions were initiated on the afternoon of the 3rd day after hatching.

All subjects receiving food or sand USs during conditioning sessions remained healthy and active throughout the experiment. Chicks receiving water USs, however, appeared weak and sluggish by the third or fourth session. One subject in Group Ran-W died on the 5th day after hatching. Late in the morning on the 5th day (immediately after Session 4), the home-box feeding regimen was changed for chicks in both groups with water as the US (Groups Dis-W and Ran-W). A large dish of dry mash was kept in the home boxes at all times, and the chicks soon pecked at and ingested the food. Water continued to be administered by hand in the dark. The seven remaining subjects regained a healthy appearance by the afternoon of the 5th day, and were exposed to three more daily conditioning sessions.

\section{RESULTS}

Approach and contact responses developed under good discriminative control of $\mathrm{CS}+$ when it was paired with food (Group Dis-F) or water (Group Dis-W).

In Group Dis-F, approach responses developed after 10 to 16 pairings of CS + with food and keycontact responses emerged after 11 to 21 pairings (Table 1). By the fifth session, key contacts occurred during $20 \%$ to $90 \%$ of CS + presentations (Figure 1, Column 1), despite omission of scheduled USs on trials when a contact occurred. On CS + trials with at least one contact, the number of contacts ranged from 1 to 5. Few, if any, responses were directed toward CS - or toward the darkened keys during ITIs. The overall number of $\mathrm{CS}+$ and $\mathrm{CS}-$ presentations with approach, key-contact, or off-key (Barrera, 1974) responses is shown for Group Dis-F in Table 2.

For subjects in Group Dis-W, approach responses developed after 42 to 53 pairings of $\mathrm{CS}+$ with water and key-contact responses emerged after 43 to 53 pairings (Table 1). No chick in this group approached or made contact with CSs during the first four sessions, and many stimulus presentations occurred while the chicks sat with eyes closed. After the change in home-box feeding conditions (between Sessions 4 and 5), key-directed approach and contact responses developed rapidly. By the seventh session, key contacts occurred during $10 \%$ to $70 \%$ of CS +

Table 1

Number of Trials to the First Key-Directed Response

\begin{tabular}{|c|c|c|c|c|c|}
\hline \multirow[b]{2}{*}{ Group } & \multirow[b]{2}{*}{ Subject } & \multicolumn{2}{|c|}{ Orient and Approach } & \multicolumn{2}{|c|}{ Key-Contact } \\
\hline & & $\mathrm{CS}+$ & CS- & CS+ & CS- \\
\hline \multirow{4}{*}{ Dis-F } & 1 & 10 & 9 & 11 & 42 \\
\hline & 2 & 15 & & 21 & \\
\hline & 3 & 16 & 20 & 16 & 34 \\
\hline & 4 & 15 & 13 & 21 & \\
\hline \multirow{4}{*}{ Dis-W } & 10 & 42 & 46 & 43 & 53 \\
\hline & 11 & 49 & 52 & 49 & \\
\hline & 12 & 53 & 58 & 53 & 58 \\
\hline & 13 & 53 & 53 & 53 & 53 \\
\hline \multirow{4}{*}{ Dis-S } & 21 & & 23 & & \\
\hline & 22 & & & & \\
\hline & 23 & & 14 & & \\
\hline & & $\begin{array}{c}\text { Green } \\
\text { CS }\end{array}$ & $\begin{array}{l}\text { Orange } \\
\text { CS }\end{array}$ & $\begin{array}{c}\text { Green } \\
\text { CS }\end{array}$ & $\begin{array}{c}\text { Orange } \\
\text { CS }\end{array}$ \\
\hline Ran-F & $\begin{array}{l}5 \\
6 \\
7 \\
8\end{array}$ & & 19 & & \\
\hline \multirow{3}{*}{ Ran-W } & 17 & 52 & 54 & 52 & 54 \\
\hline & 18 & 51 & & 51 & \\
\hline & 19 & 56 & 51 & 58 & 51 \\
\hline
\end{tabular}




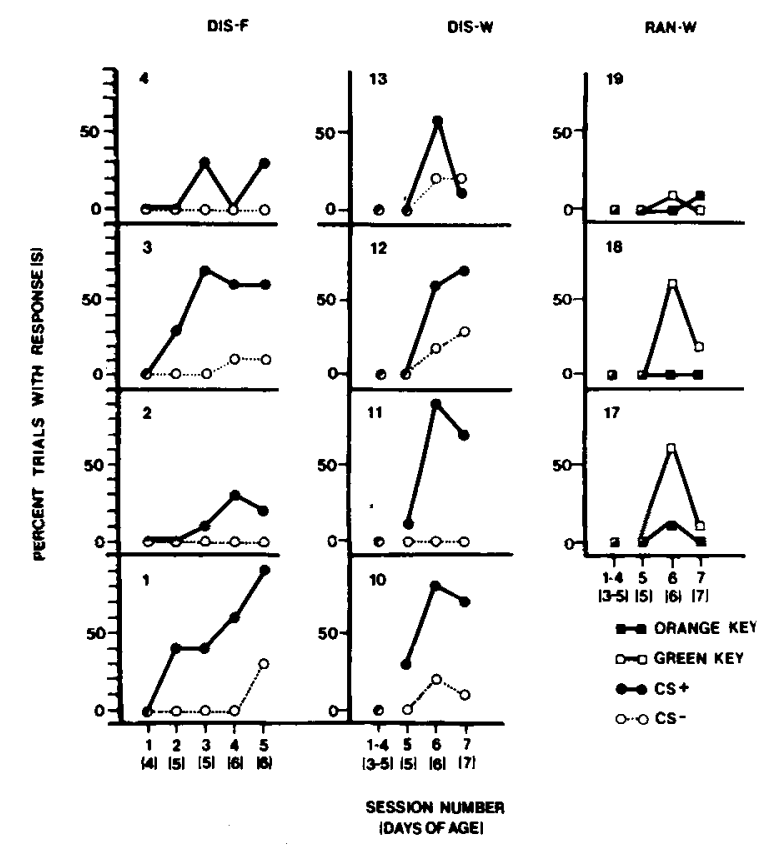

Figure 1. Percentage of CS presentations with a key-contact response, for each chick in the discriminative omission procedure with food (Column 1) and water (Column 2), and the random-control procedure with water (Column 3). In Columns 1 and 2, solid lines connect data points from each session for $\mathrm{CS}+$ presentations and hatched lines connect data points for $\mathrm{CS}$ presentations. In Column 3, solid lines connect data points for orange-key CS presentations (filled squares) and green-key CS presentations (open squares). Age of each chick during each session is shown along the abscissa.

presentations (Figure 1, Column 2), despite the omission contingency. On CS + trials with at least one key contact, the number of contacts ranged from 1 to 6. Few, if any, responses occurred to CS or to either darkened key during ITIs. Total number of CS + and CS - presentations with approach, keycontact, or off-key responses are shown for Group Dis-W in Table 2.

Approach and key-contact behaviors emerged in a saltatory fashion for most subjects in Groups Dis-F and Dis-W. The data do not suggest that key-contact responses resulted from reinforcement of successive approximations to the full sequence of appetitiveconsummatory acts. A measure which shows this effect is the number of trials with approach responses followed by presentation of the US (i.e., number of $\mathrm{CS}+$ trials with approach but no key contact) before the first key-contact response occurred. These numbers were $1,3,0$, and 4 for Subjects $1,2,3$, and 4 in Group Dis-F, respectively, and $1,0,0$, and 0 for Subjects $10,11,12$, and 13 in Group Dis-W, respectively. The first observed key-directed behavior for four of eight subjects was a complete approach and contact sequence of responses. For the other subjects, key contacts emerged after very few reinforced approach responses. Approach followed by off-key responses was rare (Table 2), and those few instances in which such responding was noted occurred after key-contact responding was already established.

In contrast to the results for the first two groups, subjects in Groups Dis-S, Ran-F, and Ran-W did not develop substantial levels of approach or key-contact responding.

Subjects in Group Dis-S with sand USs never approached or made contact with $\mathrm{CS}+$. Two chicks (Subjects 21 and 23) each approached CS - once only (Tables 1 and 2 ).

Subjects in Group Ran-F, with uncorrelated presentations of CSs and food USs, also did not contact either CS. One chick (Subject 6) approached CS once only (Tables 1 and 2).

Two of three surviving chicks in Group Ran-W (Subjects 17 and 18) showed a transient development of approach and key contacts to the green CS during Session 6 (Figure 1, Column 3). Responding returned to low levels in Session 7. Total number of CS+ and CS - presentations with approach, key-contact, or off-key responses is shown for subjects in this group in Table 2. Few approaches or contacts were directed toward the orange CS. Off-key responses were also rare, but showed a slightly higher frequency for subjects in Group Ran-W than for those in any other group (Table 2).

The form of autoshaped behavior patterns varied with the type of US. Table 3 shows the frequency of peck or drink topographies to the CSs for each chick

Table 2

Total Number of Trials with a Response

\begin{tabular}{|c|c|c|c|c|c|c|c|}
\hline \multirow[b]{2}{*}{ Group } & \multirow[b]{2}{*}{ Subject } & \multicolumn{2}{|c|}{$\begin{array}{l}\text { Orient and } \\
\text { Approach }\end{array}$} & \multicolumn{2}{|c|}{$\begin{array}{c}\text { Key- } \\
\text { Contact }\end{array}$} & \multicolumn{2}{|c|}{$\begin{array}{c}\text { Off-Key } \\
\text { Response }\end{array}$} \\
\hline & & CSt & CS- & $\mathrm{CS}+$ & CS- & CSt & $\mathrm{CS}-$ \\
\hline Dis-F & $\begin{array}{l}1 \\
2 \\
3 \\
4\end{array}$ & $\begin{array}{l}28 \\
23 \\
26 \\
23\end{array}$ & $\begin{array}{l}6 \\
0 \\
7 \\
3\end{array}$ & $\begin{array}{r}23 \\
6 \\
22 \\
6\end{array}$ & $\begin{array}{l}3 \\
0 \\
2 \\
0\end{array}$ & $\begin{array}{l}0 \\
4 \\
0 \\
0\end{array}$ & $\begin{array}{l}0 \\
0 \\
0 \\
0\end{array}$ \\
\hline Dis-W & $\begin{array}{l}10 \\
11 \\
12 \\
13\end{array}$ & $\begin{array}{r}20 \\
21 \\
14 \\
8\end{array}$ & $\begin{array}{l}7 \\
7 \\
5 \\
5\end{array}$ & $\begin{array}{r}18 \\
17 \\
13 \\
7\end{array}$ & $\begin{array}{l}3 \\
0 \\
5 \\
4\end{array}$ & $\begin{array}{l}0 \\
0 \\
1 \\
0\end{array}$ & $\begin{array}{l}0 \\
1 \\
0 \\
0\end{array}$ \\
\hline Dis-S & $\begin{array}{l}21 \\
22 \\
23 \\
24\end{array}$ & $\begin{array}{l}0 \\
0 \\
0 \\
0\end{array}$ & $\begin{array}{l}1 \\
0 \\
1 \\
0\end{array}$ & $\begin{array}{l}0 \\
0 \\
0 \\
0\end{array}$ & $\begin{array}{l}0 \\
0 \\
0 \\
0\end{array}$ & $\begin{array}{l}0 \\
0 \\
0 \\
0\end{array}$ & $\begin{array}{l}0 \\
0 \\
1 \\
0\end{array}$ \\
\hline & & G & 0 & $\mathrm{G}$ & 0 & G & 0 \\
\hline Ran-F & $\begin{array}{l}5 \\
6 \\
7 \\
8\end{array}$ & $\begin{array}{l}0 \\
0 \\
0 \\
0\end{array}$ & $\begin{array}{l}0 \\
1 \\
0 \\
0\end{array}$ & $\begin{array}{l}0 \\
0 \\
0 \\
0\end{array}$ & $\begin{array}{l}0 \\
0 \\
0 \\
0\end{array}$ & $\begin{array}{l}0 \\
0 \\
0 \\
0\end{array}$ & $\begin{array}{l}0 \\
0 \\
0 \\
0\end{array}$ \\
\hline Ran-W & $\begin{array}{l}17 \\
18 \\
19\end{array}$ & $\begin{array}{r}9 \\
11 \\
6\end{array}$ & $\begin{array}{l}3 \\
0 \\
4\end{array}$ & $\begin{array}{l}7 \\
8 \\
1\end{array}$ & $\begin{array}{l}1 \\
0 \\
1\end{array}$ & $\begin{array}{l}1 \\
3 \\
2\end{array}$ & $\begin{array}{l}2 \\
0 \\
1\end{array}$ \\
\hline
\end{tabular}

Note $-G=$ green $C S ; O=$ orange $C S$ 
Table 3

Total Number of Key-Contact Responses with Peck or Drink Topographies

\begin{tabular}{|c|c|c|c|c|c|}
\hline \multirow[b]{2}{*}{ Group } & \multirow[b]{2}{*}{ Subject } & \multicolumn{2}{|c|}{$\begin{array}{c}\text { Ballistic } \\
\text { Peck }\end{array}$} & \multicolumn{2}{|c|}{$\begin{array}{c}\text { Drinking } \\
\text { Motion }\end{array}$} \\
\hline & & $\mathrm{CS}+$ & $\mathrm{CS}-$ & $\mathrm{CS}+$ & $\mathrm{CS}_{-}$ \\
\hline \multirow{4}{*}{ Dis-F } & 1 & 60 & 4 & 2 & 0 \\
\hline & 2 & 16 & 0 & 0 & 0 \\
\hline & 3 & 53 & 2 & 1 & 0 \\
\hline & 4 & 8 & 0 & 0 & 0 \\
\hline \multirow{5}{*}{ Dis-W } & 10 & 1 & 1 & 51 & 2 \\
\hline & 11 & 2 & 0 & 50 & 0 \\
\hline & 12 & 1 & 1 & 31 & 6 \\
\hline & 13 & 1 & 5 & 10 & 1 \\
\hline & & $\begin{array}{c}\text { Green } \\
\text { CS }\end{array}$ & $\begin{array}{c}\text { Orange } \\
\text { CS }\end{array}$ & $\begin{array}{c}\text { Green } \\
\text { CS }\end{array}$ & $\begin{array}{c}\text { Orange } \\
\text { CS }\end{array}$ \\
\hline \multirow{3}{*}{ Ran-W } & 17 & 0 & 0 & 11 & 1 \\
\hline & 18 & 0 & 0 & 12 & 0 \\
\hline & 19 & 1 & 1 & 0 & 0 \\
\hline
\end{tabular}

in Groups Dis-F, Dis-W, and Ran-W. All chicks in Group Dis-F, with food as the US, generally performed rapid ballistic pecking motions toward the key with beak open, the chick's characteristic feeding response. These subjects also engaged in vigorous scratching of the Sanicell bedding beneath the CS + . In contrast, responses for chicks in Groups Dis-W and Ran-W, with water as the US, were almost exclusively characteristic drinking reactions. This form of response consisted of slow extension of the neck and head toward the key, followed by upward "scooping" or rapid "nibbling" motions of the beak during contact.

Similar feeding or drinking reactions were not observed to be elicited by the USs. After insertion of food, water, or sand in the beak, swallowing and slight, restless body movements occurred. Just after US presentations and during ITIs, most chicks exhibited "snuggling" responses (Wasserman, 1973a) directed toward their own reflections in the mirror.

\section{DISCUSSION}

The major results of the present study are consistent with the learned release hypothesis for the form of autoshaped behaviors. First, the hypothesis asserts that autoshaped behavior patterns are "preformed," phylogenetically adapted motor sequences. Inasmuch as subjects lacked experience with responding to the US used in training, the present demonstration cannot be explained in terms of transfer or reinstatement of previously learned instrumental response patterns. The omission contingency reduces the probability that responses directed toward the CS arose from adventitious response-reinforcer pairings. Presumably, the peck or drink reactions we observed have been selected during the past history of the species as highly efficient methods for achieving receipt and ingestion of small objects, such as grain, or fluids, such as water, respectively. Although the developmental history of responses observed in autoshaping with other species and USs has not been controlled in previous work, their species specificity makes plausible the general view that the form of autoshaped behaviors is importantly determined by phylogenetic organization.

Second, "learned release" assumes that the US in autoshaping need only furnish stimulation which innately identifies it as biologically significant and thereby facilitates a distinct set of species-specific motor acts. In support of this view was the finding that oral aspects of food and water, but not sand, were found to be effective USs in the present experiment. Oral stimulation is a critical factor in the chick's initial identification of food and water items (Hogan, 1973), whereas oral aspects of sand probably fail to identify the substance as biologically significant (Hogan, 1971). Additional support comes from failures to obtain appreciable autoshaped responding when food USs are presented without oral stimulation (e.g., visible but inaccessible grain; Browne, 1976; Parisi \& Matthews, 1975; Zentall \& Hogan, 1975). Further aspects of the present data also support the view that the critical function of the US is "selective facilitation," rather than elicitation, of a species-specific behavior pattern. Sand, food, and water USs merely elicited swallowing in the present subjects, yet food and water USs supported autoshaping. Autoshaped response topographies with food or water were distinct: with food USs, the form of response resembled feeding (approach, peck, scratch); with water USs, it resembled drinking (approach, sustained contact, "nibbling," or "scooping").

Third, "learned release" assumes that associative factors can determine which external stimuli will orient and release components of the facilitated motor pattern. In keeping with this assumption, $\mathrm{CS}+$ reliably controlled responding, while $\mathrm{CS}$ - and CSs uncorrelated with USs did not. Similar findings have been reported in previous studies of associative factors underlying autoshaping (Bilbrey \& Winokur, 1973; Brown \& Jenkins, 1968; Gamzu \& Williams, 1971; Wasserman, Franklin, \& Hearst, 1974).

It should be noted that an assertion that the present methods ruled out instrumental reinforcement is somewhat less secure for Group Dis-W than for Group Dis-F. To remedy the poor health of chicks in Group Dis-W, we gave them experience pecking at food, and this occurred just prior to the development of autoshaped responding. However, these subjects rarely or never were observed to perform drinking reactions to the dry mash in the home box or feeding 
reactions to $\mathrm{CS}+$ during conditioning (see Table 3 ). It would be difficult to account for the emergence of their key-directed drinking patterns in terms of instrumental-reinforcement factors, such as responseinduction or generalization from pecking and scratching food.

Onset of key-contact responding required fewer CS-US pairings for subjects in Group Dis-F with food as the US (11 to 21 pairings) than for subjects in Group Dis-W with water as the US (43 to 53 pairings). The poor health of subjects in Group Dis-W may have delayed the development of responding, a hypothesis supported by the fact that responses emerged soon after the chicks regained a healthy appearance. Perhaps these subjects experienced fewer CS-US pairings than were programmed, since their eyes were closed much of the time during early sessions. However, the age at which responding first emerged, rather than the number of prior CS-US pairings, was approximately the same (5 days) for subjects in both groups (Figure 1). A maturational factor, such as onset of a "critical period" (Hess, 1964) might explain this aspect of the results. Perhaps early CS-US pairings were ineffective for subjects in Group Dis-W because they preceded the beginning of such a critical period. Proper interpretation of the present quantitative difference in acquisition of autoshaped responding with food and water requires further parametric study.

Although "learned release" suggests an account for the form of autoshaped behaviors, a complete theory of autoshaping must take into account numerous other aspects of the phenomenon. Several factors that can affect the acquisition, maintenance, and form of autoshaped responding were obviated here. Response-reinforcer dependencies can influence the rate (Woodruff, Conner, Gamzu, \& Williams, 1977), temporal patterning (Deich \& Wasserman, 1977), and to some extent the form (Moore, 1971) of autoshaped responses after they emerge. Stimulus generalization can modulate the rate of acquisition of responding when CS and US share stimulus features in the same modality (Davol, Steinhauer, \& Lee, 1977; Sperling, Perkins, \& Duncan, 1977; Steinhauer, Davol, \& Lee, 1976, 1977). Stimulus properties of the CS, such as modality and localizability, can determine which components of the behavior pattern facilitated by the US are released and oriented in a given situation (Bilbrey \& Winokur, 1973; Hearst \& Jenkins, 1974; Redford \& Perkins, 1974; Schwartz, 1973; Wasserman, 1973b). Finally, when the CS is not initially neutral, the autoshaped behavior pattern may include an intermixture of response types determined by both CS and US (Timberlake \& Grant, 1975). Thus, "learned release" is but one of several factors which can influence the topography of the autoshaped response. The present experiment clearly revealed its powerful effects by stripping these other factors from the autoshaping procedure.

It may be noted that there is at least one autoshaping procedure in which "learned release" appears to play no direct role. In higher-order autoshaping, an already conditioned signal for a biologically important event acts as the "US" and an associative transfer of responding occurs from one signal to another. Rashotte, Griffin, and Sisk (1977) found that pecking developed to an illuminated key paired with a signal for food which already controlled pecking (directed toward the signal when it was visual, or toward the hopper when the signal was auditory). "Learned release" appears to be involved here only in first-order conditioning, i.e., the signal that later serves as US originally gains control of responding by virtue of its correlation with proximal reinforcing stimulation.

The learned-release hypothesis adds yet another facet to the broad view of autoshaping offered by Hearst and Jenkins (1974), the "sign tracking" approach. These authors outlined a comprehensive framework for results which show that organisms approach or withdraw from signals for positive or negative reinforcers. The learned-release hypothesis is in keeping with their approach, in its emphasis on associative (stimulus-reinforcer) factors in the control of stimulus-directed skeletal behaviors, and in its assertion that autoshaped behaviors are phylogenetically organized. "Sign tracking" proposes that autoshaping is based upon an innate predisposition to locomote toward signals for forthcoming positive reinforcers. "Learned release" complements this view by suggesting a biological account for the topography of responses which comprise locomotion toward, as well as contact and manipulation with, the signal. In the case of signals for negative reinforcers, "sign tracking" suggests that organisms will often locomote away from the signal. "Learned release" assumes that signals for negative reinforcers can evoke defensive (fight or flight; Hess, 1948) reactions aroused by the aversive US. In some instances, the conditioned response may involve locomotion away from the CS (flight), but under other conditions, it may entail approach and contact with the signal (fight reactions, e.g., Rachlin, 1969). It must be emphasized that "learned release" does not provide a complete theory of autoshaping, but, rather, identifies several important determinants of the form and direction of autoshaped behaviors which must be taken into account by any general theory of the phenomenon.

From an ethological perspective, the present experiment may be viewed as a controlled simulation of the events responsible for visual recognition of food and water in the newly hatched chick. Pairings of a distal visual stimulus with proximal stimulation arising from food or water in the beak led to the 
development of species-specific feeding or drinking reactions directed toward the visual stimulus. The present procedure departed from the natural state of affairs in two obvious respects. First, distal and proximal stimuli emanated from separate locations (a chamber wall and the experimenter's hand, respectively). In the wild, distal and proximal stimuli are but two aspects of the same object, e.g., visual and oral aspects of grains or droplets of water. Second, the experimenter arranged visual-oral stimulus pairings by force-feeding methods. How are such correlations arranged in the wild? Lorenz's notion of the "innate schoolmaster" (Lorenz \& Leyhausen, 1973) provides a plausible, albeit speculative, answer. Lorenz cited a number of examples in which the instinctive behavior of one animal teaches its offspring or other conspecifics about some biologically important event. In altricial species, such as the pigeon, the behavior of the parents during feeding of the young may arrange visual-oral stimulus pairings for the naive squab (Woodruff et al., Note 1; Wortis, 1969). In the case of a precocial species, such as the domestic chicken, visual-oral stimulus pairings responsible for food or water recognition may be established by the animal's own instinctive behavior. Soon after hatching, domestic chicks possess a strong tendency to explore and peck at objects with certain visual characteristics (Fantz, 1957; Rheingold \& Hess, 1957). Although natural grains or insects and droplets of water are not initially recognized as food or water on a visual basis, they share many of these visual characteristics. The chick's exploratory pecking tendency virtually assures initial experience with pairings of the visual and oral aspects of food and water. Subsequent encounters with similar visual stimuli release distinct feeding or drinking reactions, respectively.

A similar account may explain the ontogeny of visual recognition of objects other than food and water (Woodruff, Note 2). For example, the behavior of the mother hen during brooding of her chicks may arrange initial visual-thermal stimulus pairings for the naive chick (Hogan, 1974). After such initial experience, the sight of the mother hen is recognized as a source of heat and releases a preorganized sequence of approach, pecking, and "snuggling" (Wasserman, 1973a, 1974).

"Learned release" and "innate schoolmaster" notions together specify a manner by which the young of a species could be educated about significant items in its environment via an associative process akin to autoshaping. Indeed, autoshaping in adult organisms may be characterized as reactivation of that process which originally led to visual recognition of the reinforcer during ontogeny. To the extent that further work with other species and USs extends the generality of the present findings, these hypotheses could furnish an important principle of ontogenetic behavioral organization.

\section{REFERENCE NOTES}

1. Woodruff, G., Morrison, R. R., \& Williams, D. R. Consummatory fixed-action patterns underlying conditioned keypecking in the pigeon. Paper and videotape presented at the Fifteenth Annual Meetings of the Psychonomic Society, Boston, November 1974 .

2. Woodruff, G. Autoshaping: A "learned release" hypothesis. Paper presented at the meetings of the Eastern Psychological Association, Philadelphia, April 1974.

\section{REFERENCES}

Asratyan, E. A. Compensatory adaptations, reflex activity, and the brain. Oxford: Pergamon Press, 1965.

Barrera, F. J. Centrifugal selection of signal-directed pecking. Journal of the Experimental Analysis of Behavior, 1974, 22. 341-355.

Bilbrey. J, \& Winokur, S. Controls for and constraints on autoshaping. Journal of the Experimental Analysis of Behavior. 1973, 20, 323-332.

Brown, P. L.. \& Jenkins, H. M. Auto-shaping of the pigeon's key-peck. Journal of the Experimental Analysis of Behavior. $1968,11,1-8$.

Browne, M. P. The role of primary reinforcement and overt movements in autoshaping. Animal Learning \& Behavior, 1976, 4. $287-292$.

Bullock. H. T. Origins of patterned nervous discharge. Behaviour, 1961, 17, 48-60.

Cralg, W. Observations on doves learning to drink. Journal of Animal Behavior, 1912, 3. 273-279.

Davol, G. H., Steinhauer, G. D., \& Lee, A. The role of preliminary magazine training in acquisition of the autoshaped key peck. Journal of the Experimental Analysis of Behavior, 1977, 28, 99-106.

Deich, J. D., \& Wasserman, E. A. Rate and temporal pattern of key pecking under autoshaping and omission schedules of reinforcement. Journal of the Experimental Analysis of Behavior, 1977, 27, 399-405.

FANTZ, R. L. Form preferences in newly hatched chicks. Journal of Comparative and Physiological Psychology, 1957, 50, 422-430.

Gamzu, E., \& Williams, D. R. Classical conditioning of a complex skeletal response. Science, 1971, 171, 923-925.

Gamzu, E., \& Williams, D. R. The source of keypecking in autoshaping. Animal Learning \& Behavior, 1975, 3, 37.42.

Gellermans, L. W. Chance orders of alternating stimuli in visual discrimination experiments. Journal of Genetic Psychology, 1933, 42, 206-208.

Glickman, S. E., \& SChifF, B. A. A biological theory of reinforcement. Psychological Review, 1967, 74, 81-109.

Hearst, E., \& Jenkins, H. M. Sign-tracking: The stimulusreinforcer relation and directed action. Austin, Texas: Psychonomic Society, 1974.

Hess, E. H. Imprinting in birds. Science, 1964, 146, 1128-1139.

HEss. W. R. The functional organization of the diencephalon. New York: Grune and Stratton, 1948.

Hogan, J. A. The development of a hunger system in young chicks. Behaviour, 1971, 39, 128-201.

Hogan. J. A. How young chicks learn to recognize food. In R. A. Hinde \& J. Stevenson-Hinde (Eds.), Constraints on learning. New York: Academic Press, 1973. Pp. 119-139.

Hogan. J. A. Responses in Pavlovian conditioning studies. Science. 1974, 186. 156-157.

Hunt, G. L., \& Sмітн, W. J. Pecking and initial drinking responses in young domestic fowl. Journal of Comparative and Physiologicul Psychology, 1967, 64, 230-236.

Jenkins, H. M.. \& Moore. B. R. The form of the autushaped response with food or water reinforcers. Joumal of the Experimental Analysis of Behavior, 1973, 20. 163-181.

LORENZ. K.. \& LeYhausen. P. Motivation of human and animal behavior. New York: Van Nostrand Reinhold, 1973. Pp. 348ff. 
Marley, E., \& Morse, W. H. Operant conditioning in the newly hatched chicken. Journal of the Experimental Analysis of Behavior, 1966, 9, 95-103.

Moore, B. R. On directed respondents. PhD thesis, Stanford University, 1971.

Moore, B. R. The role of directed Pavlovian reactions in simple instrumental learning in the pigeon. In R. A. Hinde \& J. Stevenson-Hinde (Eds.), Constraints on learning. New York: Academic Press. 1973. Pp. 159-188.

Parisi, T., \& Matthews, T. J. Pavlovian determinants of the autoshaped keypeck response. Bulletin of the Psychonomic Society, 1975, 6, 527-529.

Peterson. G. B., Ackil, J. E., Frommer, G. P., \& Hearst, E. S. Conditioned approach and contact behavior toward signals for food and brain-stimulation reinforcement. Science, 1972, 177 , 1009-1011.

RACHLIN, H. Autoshaping of keypecking in pigeons with negative reinforcement. Journal of the Experimental Analysis of Behavior. 1969, 12. 521-531.

Rashotte. M. E., Griffin, R. W., \& Sisk, C. L. Second-order conditioning of the pigeon's keypeck. Animal Learning \& Behavior, 1977, 5, 25-38.

Redford, M. E., \& Perkins, C. C. The role of autopecking in behavioral contrast. Journal of the Experimental Analysis of Behavior. 1974, 21, 145-150.

Rescorla, R. A. Pavlovian conditioning and its proper control procedures. Psychological Review, 1967, 74, 71-80.

Rheingold, H. L., \& Hess, E. H. The chick's "preference" for some visual properties of water. Joumal of Comparative and Physiological Psychology, 1957, 50, 417-421.

Roberts, W. W., \& Bergquist, E. H. Attack elicited by hypothalamic stimulation in cats raised in social isolation. Journal of Comparative and Physiological Psychology, 1968, 66. $590-595$.

Schwartz, B. Maintenance of key pecking by responseindependent food presentation: The role of the modality of the signal for food. Journal of the Experimental Analysis of Behavior, 1973, 20, 17-22.

Schwartz, B., \& GamzU. E. Pavlovian control of operant behavior: An analysis of autoshaping and its implications for operant conditioning. In W. K. Honig \& J. E. R. Staddon (Eds.), Handbook of operant behavior. Englewood Cliffs, N.J: Prentice-Hall, 1977. Pp. 53-97.

SEGAL, E. F. Induction and the provenance of operants. In R. M. Gilbert \& J. R. Millenson (Eds.), Reinforcement: Behavioral analyses. New York: Academic Press, 1972. Pp. 1-34.

ShefField, F. D. Relation between classical conditioning and instrumental learning. In W. F. Prokasy (Ed.), Classical conditioning. New York: Appleton-Century-Crofts, 1965. Pp. 302-322.

Sperl.ing, S. E., Perkins, M. E., \& Duncan, H. J. Stimulus generalization from feeder to response key in the acquisition of autoshaped pecking. Journal of the Experimental Analysis of Behavior, 1977, 27, 469-478.
Staddon, J. E. R., \& Simmelhag, V. L. The "superstition" experiment: A re-examination of its implications for the principles of adaptive behavior. Psychological Review. 1971. 78. 3-43.

Steinhauer, G. D., Davol, G. H., \& Lee, A. Acquisition of the autoshaped key peck as a function of amount of preliminary magazine training. Joumal of the Experimental Analysis of Behavior, 1976, 25, 355-359.

Steinhauer, G. D., Davol, G. H., \& Lee, A. A procedure for autoshaping the pigeon's key peck to an auditory stimulus. Journal of the Experimental Analysis of Behavior, 1977, 28. 97-98.

Timberlake, W., \& Grant, D. L. Auto-shaping in rats to the presentation of another rat predicting food. Science, 1975. 190. 690-692.

VALENSTEIN, E. S. Behavior elicited by hypothalamic stimulation: A prepotency hypothesis. Brain. Behavior. and Evolution. 1969, 2, 295-316.

von Holst, E., \& von Saint Paul, U. On the functional organisation of drives. Animal Behaviour, 1963, 11, 1-20.

Wasserman, E. A. Pavlovian conditioning with heat reinforcement produces stimulus-directed pecking in chicks. Science, 1973, 181, 875-877. (a)

WassERman, E. A. The effect of redund ant contextual stimuli on autoshaping pigeon's keypeck. Animal Learning \& Behavior. 1973, 1, 198-206. (b)

Wasserman, E. A. Reply to Hogan's comment. Science, 1974, 186. 157.

Wasserman, E. A.. Franklin, S. R., \& Hearst, E. Pavlovian appetitive contingencies and approach versus withdrawal to conditioned stimuli in pigeons. Journal of Comparative and Physiological Psychology, 1974, 86, 616-627.

Williams, D. R., \& Williams, H. Auto-maintenance in the pigeon: Sustained pecking despite contingent non-reinforcement. Journal of the Experimental Analysis of Behavior, 1969, 12. 511-520.

Woodruff, G., Conner, N., Gamzu, E., \& Williams, D. R. Associative interaction: Joint control of key pecking by stimulus reinforcer and response-reinforcer relationships. Journal of the Experimental Analysis of Behavior, 1977, 28, 133-144.

Woodruff, G.. \& Williams, D. R. The associative relation underlying autoshaping in the pigeon. Journal of the Experimental Analysis of Behavior, 1976, 26, 1-13.

WORTIS, R. P. The transition from dependent to independent feeding in the young ring dove. Animal Behaviour Monographs, 1969, 2, 1-54.

Zentall, T. R., \& Hogan, D. E. Key pecking in pigeons produced by pairing keylight with inaccessible grain. Journal of the Experimental A nalysis of Behavior, 1975, 23, 199-206.

(Received for publication July 28, 1977; revision accepted February 2, 1978.) 